tions. But here and there, also, one does feel rather surprised at the advice given. 'Thus, on p. 321, the practitioner is instructed in a "Rule," with all the emphasis of heavy type, never to employ a tonsillotome, the morcelleur being recommended in its stead. Tonsillectomy receives no mention at all. But all this is merely the way in which the author removes the fear of post-operative hæinorrhage from the troubles that beset the path of the occasional operator!

We commend strongly the author's plan of inserting a section, in the "treatment" of each disease, dealing with "what to avoid," as well as one of "what to do." Among the former, in the case of acute purulent otitis media, we read: "Do not look upon this disease as a simple malady which always gets well of its own accord." And in the same connection we are warned not to "infect the ear with polychromatic mixtures, so-called analgesics and antiseptics," or to prescribe injections before the membrane is ruptured. Moreover, the thoroughly sound and sensible teaching is promulgated to open the membrane early and not to wait until it ruptures spontaneously.

But the book is full of giod advice, clearly enunciated, and, as a rule, based upon orthodox and well-tried principles.

We were almost persuaded to be enthusiastic in our praise, but that is merely the effect of the wonderful series of diagrams.

There is no index.

Dan McKenzie.

The Auditory Organ in War Time. By E. J. Moure and P. Pietri. Paris: L. Fournier, 1916.

This pamphlet, reprinted from the Archives de Médicine et de Pharmacie Militaires (June and August, 1916), is an elaborate essay divided into two parts. The first deals with "labyinthism" and functional examination; the second with cerebral deafness, malingering, and exaggeration. The authors point out the necessity of very great care in physical and functional examination and in obtaining every possible information as to original causation, etc. They advocate repeated examinations, static and auditory, of the organ of hearing by the most recent methods, considering such examinations as necessary and even indispensable for the detection of conscious or unconscious aggravations by the patient or to bridge the lacuna of earlier investigations. The expert otologist will find that in cases of injury of the ear, the importance of the blow, or of the shell shock, is not always in relation with the auditory and static disorders. The authors deprecate undue precipitancy in diagnosis - " Review in six months or a year for a definite opinion" is the rubric upon which they insist.

Macleod Yearsley.

\title{
THE LATE DR. JULES BROECKAERT.
}

IN addition to what was intimated in our last issue, we learn that the movement for subscriptions from the Otulogical and LaryngologicaI Sections of the Royal Society of Medicine was started by Sir Felix Semon, who laid the state of matters before the President of the Section, and at the same time subscribed five guineas.

We understand at the same time that Sir Felix applied to Dr. Emil Mager, of New York, and to Prof Burger, of A msterdam, to interest 
American and Dutch Oto-laryngologists in the movement. The result has been very gratifying. Dr. Mayer has sent Sir Felix a preliminary subscription of $£ 100$, raised among American Oto-laryngologists, under the auspices of the Presid"nts of the various special societies, with himself as treasurer, with the plea-ing intelligence that an equal amount may be expected later.

Prof. Burger has sent the handsome contribution of $21167 s .9 d$, coming from the members of the Dutch Oto-laryngolugical Societies. In addition, the following subscriptions are gratefully acknowledged :

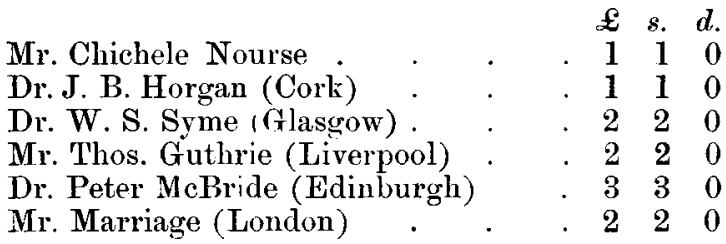

NOTES AND QUERIES.

"Mr Step-Child, Otro-Laryngology."

One can imagine Madam Medicine using these words to introduce Oto-Laryngology to the world at large on certain State and ceremonial occasions.

'To some of our readers the phrase may perhaps sound rather like an echo of "old unhappy far-off things, and battles long ago," as quite a few years have elapsed since even a mild protest has had to be nttered at any neglect of our speciality in general circles.

But it happens now and then that, in spite of all its prominence in the van of the advance-guard of Medicine, Oto-Laryngology has still occasionally to submit to such neglect as would suggest that in the ideas of some of our confrères, even at this time of day and after all we have done, we still must occupy the unhonoured place of a child born to the bar sinister.

Here, for example, we have the last issue for the year that is just gone of our respected contemporary, the Lancet (December 30,1916) in a periscopic view of the activities of medicine during 1916, finding room for an account of things done in "Surgery," "Obstetrics and Gynæcology," "Ophthalmology," "Neurology," "Electro-Therapeutics," including also reports from remote corners like "Tropical and Exotic Medicine," but omitting any mention whatever of any work in Oto. Laryngology, save where a brief and passing glance is made, under the heading of "Surgery," at some of Mr. Irwin Moore's new endoscopic instruments.

Even in the allusions to shell-shock there is no suggestion that the voice or. the hearing is ever affected.

Is it because no progress has been made in our speciality during the year? Or is it possible that the "Twilight Sleep" of the Obstetric Section has extended the range of its activities and has fallen upon the Oto-Laryngological correspondent of the Lancet?

Or is it simply that Oto.Laryngology was forgotten?

At all events we venture to express the hope, now that attention has been directed to it, that the omission will be made good by another year. And in the meantime we can, without displaying any undue conceit, advise all who desire to learn what progress our speciality has made in 1916 to consult the files of the Journal or Lartngologt, Rhinology, and Otologr.-D. M. 